\title{
Mechanical characterization of composites prepared from WC powders coated with Ni rich binders
}

\author{
C.M. Fernandes ${ }^{a}$, A.M.R. Senos ${ }^{a, *}$, M.T. Vieira ${ }^{b}$, J.M. Antunes $^{c}$ \\ a Department of Ceramics and Glass Engineering, CICECO, University of Aveiro, 3810-193 Aveiro, Portugal \\ ${ }^{\mathrm{b}}$ ICEMS, Mechanical Engineering Department, Polo 2 of University of Coimbra, 3030-201 Coimbra, Portugal \\ ${ }^{c}$ CEMUC, Mechanical Engineering Department, Polo 2 of University of Coimbra, 3030-201 Coimbra, Portugal
}

Received 6 June 2007; accepted 3 December 2007

\begin{abstract}
In this study composite powders of $\mathrm{WC}$ and $\mathrm{Ni} / \mathrm{Fe} / \mathrm{Cr}$ were prepared in an innovative way, which consists of the sputter-deposition of the metallic binder onto the tungsten carbide particles. Compacts of coated powders were sintered by conventional vacuum sintering followed by hot isostatic pressing (HIP) to reach almost full densities. In order to evaluate the mechanical properties of reduced specimens size (microcomponents), depth-sensing indentation equipment was used. This method enabled the evaluation of the hardness, $H$, Young's modulus, $E$, and the yield stress, $\sigma_{\mathrm{y}}$, in a non-destructive way, using only one sample. For the composites of sputter-coated WC$\mathrm{Ni} / \mathrm{Fe} / \mathrm{Cr}$ the results showed an effective reduction of $H$ and $E$ due to the properties of $\mathrm{Ni}$ and the binder characteristics of the coated powders, such as uniform distribution and nanometer structure.
\end{abstract}

(c) 2007 Elsevier Ltd. All rights reserved.

Keywords: Sputtering; Tungsten carbide; Nickel; Coated powders; Mechanical properties

\section{Introduction}

Hard metal has been industrially produced since the 1920 s and nowadays represents more than $40 \%$ of the cutting tool market [1]. Due to their technological importance these composites of WC, which are formed using a transition metal binder, usually cobalt but to a lesser extent iron or nickel, have been subject to a great deal of investigation in order to optimize the compositions and the processing leading to the highest mechanical properties [2-7]. During the last few decades, the deployment of cobalt natural resources and the increasing demands on material performance has directed the research mainly towards the search and optimization of new binder compositions and the development of specific coatings to improve the useful properties $[8,9]$. On the other hand, the industrial processing of these composites has made very little difference,

\footnotetext{
* Corresponding author. Tel.: +351 234370257; fax: +351 234425300.

E-mail address: anamor@cv.ua.pt (A.M.R. Senos).
}

although new emerging technologies for powder metallurgy are currently being researched with a view to industrial implementation [10-12].

In this study, an innovative method of preparing composite powders was used, consisting of the sputtering of the metallic binder onto the WC particles. The coated powders resulting from this technique show a very high uniformity of binder distribution associated with a nanocrystalline structure. The surface properties of the particles are changed, increasing the powder's flowability, pressing behaviour and sinterability in such a way that easier powder processing can be adopted [13-17]. One of the benefits comes from the possibility of shaping without a pressing binder, therefore eliminating the long milling step used in the conventional hard metal processing to add the binder and to prepare the composite powders, and also the subsequent drying of the slurry and the burnout of the pressing binder. Moreover, due to the high uniformity of the binder's distribution and its nanometer structure, liquid phase sintering is more efficient, leading to high density 
compacts at lower temperatures [15-17]. Additionally, by eliminating the milling and the pressing binder burnout steps, the processing is moving towards a cleaner technology with environmental and health benefits.

Weighing up the benefits of the low binder content needed to coat the particle surfaces using this technique (i.e. for WC particles with $2-10 \mu \mathrm{m}, \sim 4 \mathrm{wt} . \%$ of stainless steel AISI 304, will be enough for a complete particle coverage [13-18]) together with the high sinterability of the sputtered powders against the relatively high cost of the sputtering step, points to the benefits of this methodology: an innovative technological process with interesting prospects in the production of powders with low binder content for high hardness applications.

Previous studies were dedicated to the study and optimization of the surface characteristics in sputtered powders and consequences on the powder processing [13-18]. In this study, composites of $\mathrm{WC}$ and low $\mathrm{Ni} / \mathrm{Fe} / \mathrm{Cr}$ binder content (4-7 wt.\%) were prepared using both the sputtering technique and the standard conventional mixture, in order to highlight the role of sputter coating powders on the mechanical properties.

A novel method was used in order to get the best possible measurements of mechanical characteristics using only one test - depth-sensing indentation. This methodology is particularly appropriate for the characterization of materials prepared on a laboratorial scale with equipment that often limits the amount and the size of the samples, as was the case here. This is a problem that researchers have to face frequently. The reverse analysis method has been successfully applied to characterize single phase materials [19] but had not previously been tested in multi-phase, composite materials. This method was therefore first applied to a commercial WC-Co sample, whose mechanical characteristics had been characterized in previous studies, before it was used to measure the mechanical properties of the coated and conventionally prepared $\mathrm{WC}-\mathrm{Ni}$ rich binder samples.

\section{Experimental procedure}

The starting powder was fully carburized WC (H.C. Starck, HCST-Germany) with a particle size of $2-10 \mu \mathrm{m}$. The WC powder particles were coated with $\mathrm{Ni} / \mathrm{Fe} / \mathrm{Cr}$ binders using modified d.c. magnetron sputtering equipment and previously selected deposition parameters, which are described elsewhere [14]. Two coated powders, C-WC1 and C-WC2, with different binder contents $(<8 \mathrm{wt} . \%)$ were investigated. For comparison a conventional mixture of nickel (Goodfellow NI006021/11), iron (Goodfellow FE006020) and chromium (Goodfellow CR006021/22) powders was performed with the uncoated WC powder and $1.5 \mathrm{wt} . \%$ of paraffin wax, named M-WC.

Pellets of $\sim 10 \mathrm{~mm}$ diameter were subjected to cold isostatic pressing (CIP), at a maximum pressure of $\sim 330 \mathrm{MPa}$. The compacts underwent conventional vacuum sintering to a maximum temperature of $1510^{\circ} \mathrm{C}$, for $1 \mathrm{~h}$, at a pressure of $20 \mathrm{~Pa}$. To simplify the experimental procedure, the same sintering cycle was used for coated and conventionally prepared powders, although higher densifications are attained for coated powders, due to their higher reactivity. Finally, to attain almost complete densification, the pre-sintered samples were submitted to hot isostatic pressing (HIP) at $1550{ }^{\circ} \mathrm{C}$, for $2 \mathrm{~h}$ at a pressure of $30 \mathrm{MPa}$. For each composition a set of 4-6 samples were sintered.

The density of the sintered samples was determined using the Archimedes' method. Phase identification was performed by X-ray diffraction (XRD, Rigaku PMGVH). Optical microscopy (Zeiss, Jenaphot 2000) and scanning electron microscopy (SEM, Hitachi-S4100) were used to characterize the microstructure of polished surfaces chemically etched with Murakami's reagent, ${ }^{1}$ for $2 \mathrm{~min}$, to reveal the grain boundaries. WC average grain size and size distribution were measured using the linear intercept method [20] on the SEM micrographs. Random straight lines were drawn across the micrographs and the length of the intercepts with the WC grains were measured and averaged (at least 300 intercepts per sample were used). Fullman's formula was applied to transform the twodimensional mean intercept, 1 , into a three-dimensional mean grain size, $\bar{G}$, using a transformation factor of 1.5 [20]. The contiguity, $C$, was also determined using nearly 100 measurements from the optical micrographs and applying the following equation, with the assumption of a Gaussian grain size distribution [21]:

$C=1-V_{\mathrm{b}}^{0.644} \exp (0.391 \times V)$

where $V_{\mathrm{b}}$ is the volume fraction of binder and $V$ is the coefficient of variation of $\mathrm{WC}$ grain size distribution ( $V=\sigma_{\mathrm{WC}} / \bar{G}_{\mathrm{WC}}$ where $\sigma_{\mathrm{WC}}$ is the standard deviation and $\bar{G}_{\mathrm{WC}}$ is the mean carbide grain size).

The chemical characterization of the sintered samples was obtained using an electron microprobe (EMPASX50, Cameca) and the final carbon content was determined by automatic direct combustion (LECO CS $200 \mathrm{IH}$ ).

The hard metal samples were mechanically characterized using depth-sensing indentation equipment (Fischerscope H100). In order to obtain representative average values for the evaluated properties, 75 tests were performed on different surface points of each samples per set. In each test the load was increased in steps, from the first load of $0.4 \mathrm{mN}$ until a nominal load of $500 \mathrm{mN}$. Sixty steps were used for both loading and unloading, with a $0.5 \mathrm{~s}$ delay between each step. Two creep periods of $30 \mathrm{~s}$ were performed during the tests: at the maximum load and at the lowest load. The values of the 75 tests performed on each sample were used for the direct determination of the hardness, $H$, and calculation of the Young's modulus, $E$, and of the compressive rupture strength, $\sigma_{\mathrm{r}}$. In order to evaluate

\footnotetext{
${ }^{1}$ A solution of potassium ferricyanide $(10 \mathrm{~g})$ and sodium hydroxide $(10 \mathrm{~g})$ in distilled water $(100 \mathrm{ml})$.
} 
the effectiveness of this method, a commercial sample of WC-Co with 4 wt.\% of binder was first characterized. Additionally, the hardness of this standard sample was also measured using Vickers hardness tester (Zwick/Roell ZHU) with a load of $293 \mathrm{~N}$ and dwell time of $15 \mathrm{~s}$, and the dynamic Young's modulus, $E$, was yet determined by the impulse excitation vibration method at room temperature using a sample of dimensions $50 \times 12 \times 1.5 \mathrm{~mm}^{3}$.

The fracture toughness, $K_{\mathrm{c}}$, was determined in WC-Ni/ $\mathrm{Fe} / \mathrm{Cr}$ composites from the measurements of the Palmqvist radial cracks at the corners of Vickers hardness indentations (load, $98 \mathrm{~N}$ ), using the formula [22]:

$K_{\mathrm{c}}=0.087 \sqrt{H W}$

where $H$ is the hardness and $W=P / L_{\mathrm{T}}, P$ is the applied load and $L_{\mathrm{T}}$ the total length of cracks.

\section{Results and discussion}

\subsection{Chemical and morphological characterization}

The composites of $\mathrm{WC}-\mathrm{Ni} / \mathrm{Fe} / \mathrm{Cr}$ prepared by conventional mixing (M-WC) and by sputter-deposition (C-WC) had final metal amounts that varied between 4 and 7 wt.\% (Table 1). The chemical characterization of the binder was performed by EPMA analysis after sintering

Table 1

Final binder elements and carbon percentages

\begin{tabular}{llllll}
\hline Samples & $\begin{array}{l}\mathrm{Fe}^{\mathrm{a}} \\
(\text { wt.\%) }\end{array}$ & $\begin{array}{l}\mathrm{Ni}^{\mathrm{a}} \\
(\text { wt.\%) }\end{array}$ & $\begin{array}{l}\mathrm{Cr}^{\mathrm{a}} \\
(\text { wt.\%) }\end{array}$ & $\begin{array}{l}\text { Total } \\
(\text { wt.\%) }\end{array}$ & $\begin{array}{l}\mathrm{C}^{\mathrm{b}} \\
(\mathrm{wt} . \%)\end{array}$ \\
\hline $\mathrm{C}-\mathrm{WC1}$ & $1.5 \pm 0.3$ & $2.3 \pm 0.4$ & $0.1 \pm 0.0$ & $3.9 \pm 0.7$ & - \\
$\mathrm{C}-\mathrm{WC2}$ & $1.3 \pm 0.3$ & $4.3 \pm 0.5$ & $0.4 \pm 0.1$ & $6.0 \pm 0.9$ & 5.62 \\
M-WC & $1.0 \pm 0.2$ & $5.9 \pm 0.6$ & $0.1 \pm 0.0$ & $7.0 \pm 0.8$ & 5.60 \\
\hline
\end{tabular}

${ }^{\text {a }}$ EPMA analysis.

b Automatic direct combustion.
(Table 1). $\mathrm{Ni}$ is present in the highest percentage for all the compositions, followed by $\mathrm{Fe}$. $\mathrm{Cr}$ is a minor composition, not exceeding $7 \mathrm{wt} . \%$ of the total binder amount, in any case. Moreover, the $\mathrm{Fe}$ and $\mathrm{Cr}$ amounts are near constant for the three samples. The final binder amount (Table 1) was calculated as the summation of $\mathrm{Ni}, \mathrm{Fe}$ and $\mathrm{Cr}$ contents in each samples set. No significant carbon losses have been found in final compositions, as described by LECO analysis (Table 1).

The XRD patterns in Fig. 1 show that hexagonal WC and f.c.c. rich $\mathrm{Ni}$ phases are the phases identified in coated and conventionally prepared composites; graphite and $\eta$ phases were not discernible. The $\mathrm{Fe}$ and $\mathrm{Cr}$ elements appeared to be in solid solution in the Ni phase.

High apparent density values, $\rho_{\text {app }}$, were attained after sintering (Table 2). The correspondent relative densities, $\rho_{\mathrm{r}}$, vary from $\sim 94 \%$ to $\sim 99 \%$, considering the theoretical density, $\rho_{\text {th }}$, calculated by the mixing rule where $\rho_{\text {th }}=15.63 \mathrm{~g} \mathrm{~cm}^{-3}$ for WC and $\rho_{\text {th }}=8.9 \mathrm{~g} \mathrm{~cm}^{-3}$ for f.c.c. $\mathrm{Ni}$ (the effect of $\mathrm{Fe}$ and $\mathrm{Cr}$ on the density was neglected). The highest $\rho_{\mathrm{r}}$ value $(99 \%)$ was attained for the coated powder with $6 \mathrm{wt} . \%$ of binder (C-WC2), whereas the densification of the conventionally prepared powder (M-WC), with an equivalent amount of binder, showed the lowest value, $\rho_{\mathrm{r}} \sim 94 \%$. For the coated powders, even $4 \mathrm{wt} . \%$ of binder (C-WC1, Table 2) was enough to attain high densification, $\rho_{\mathrm{r}} \sim 97 \%$. These results demonstrate the improvement of the sinterability in sputtered-coated powders, already reported in previous studies [14-17], showing that it is possible to achieve higher density materials than those conventionally prepared, using lower binder content.

The microstructures of the samples were observed by optical and SEM microscopy, in Figs. 2 and 3, respectively. The optical microstructures of the samples C-WC2 and MWC, presented in Fig. 2, show that the microstructures of WC grains and the binder phase have greater tonal variation under optical observation than under the correspon-

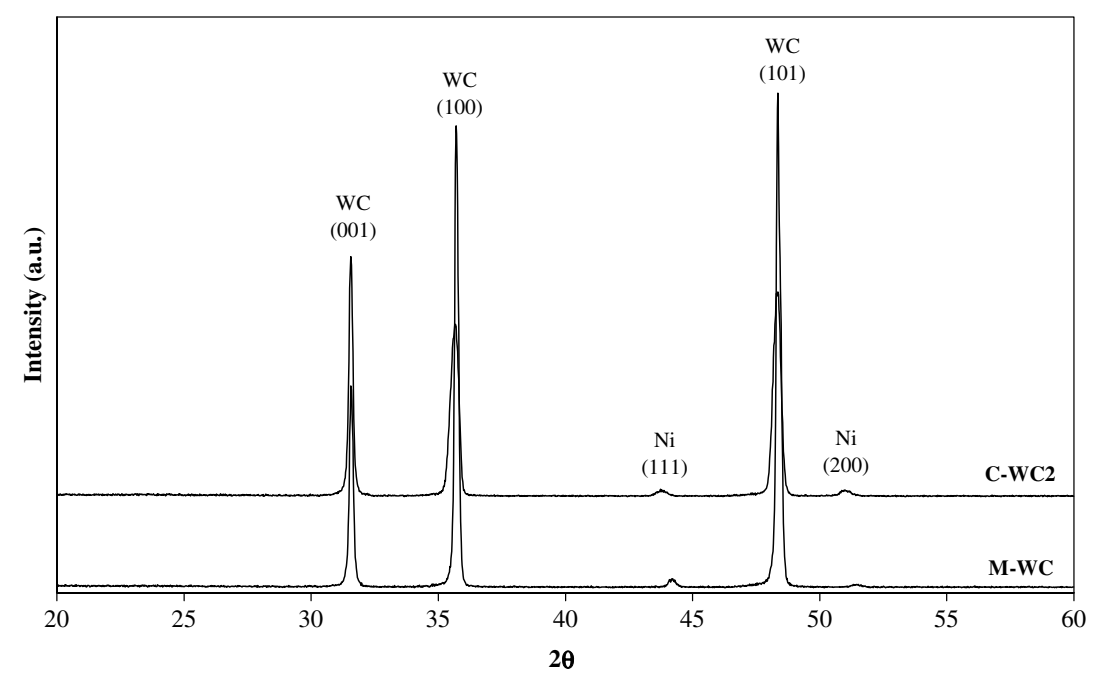

Fig. 1. XRD diffraction patterns of M-WC and C-WC2 composites. 
Table 2

Physical characteristics of the $\mathrm{WC}-\mathrm{Ni} / \mathrm{Fe} / \mathrm{Cr}$ composites

\begin{tabular}{|c|c|c|c|c|c|c|c|}
\hline Samples & $\rho_{\mathrm{app}}\left(\mathrm{g} \mathrm{cm}^{-3}\right)$ & $\rho_{\text {th }}\left(\mathrm{g} \mathrm{cm}^{-3}\right)$ & $\rho_{\mathrm{r}}(\%)$ & $D(\mu \mathrm{m})$ & $G(\mu \mathrm{m})$ & $\bar{G}(\mu \mathrm{m})$ & $C$ \\
\hline $\mathrm{C}-\mathrm{WC} 1$ & $14.7 \pm 0.1$ & 15.17 & $97 \pm 1$ & $1.7-10$ & $2.0-9$ & $4.4 \pm 1.9$ & - \\
\hline $\mathrm{C}-\mathrm{WC2}$ & $14.8 \pm 0.1$ & 14.95 & $99 \pm 1$ & $1.7-10$ & $2.0-10$ & $4.3 \pm 1.9$ & $0.62 \pm 0.06$ \\
\hline M-WC & $13.9 \pm 0.1$ & 14.84 & $94 \pm 1$ & $0.4-4.2$ & $1.5-8$ & $3.4 \pm 1.7$ & $0.60 \pm 0.06$ \\
\hline
\end{tabular}

$\rho_{\text {app }}$, apparent density; $\rho_{\text {th }}$, theoretical density; $\rho_{\mathrm{r}}$, relative density; $D$, initial particle size; $G$, grain size; $\bar{G}$, mean grain size; $C$, contiguity.
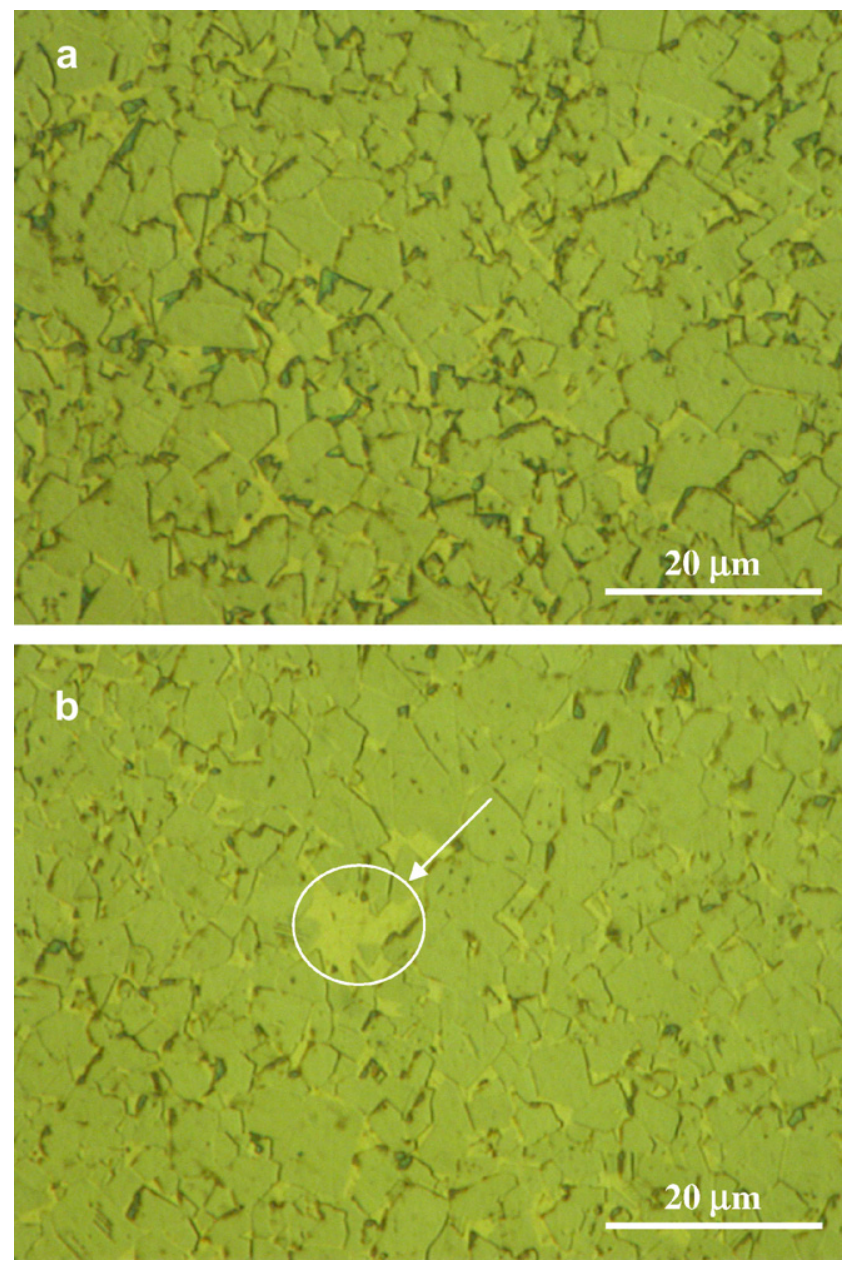

Fig. 2. Optical micrographs: (a) C-WC2 and (b) M-WC. The surrounding area shows the heterogeneity of binder distribution.

dent SEM analysis (Fig. 3): the WC phase has a darker grey and the binder phase a grey colour. The binder phase is spread between the $\mathrm{WC}$ grains since it constituted a viscous phase at the sintering temperatures. In Fig. 2a C-WC2 shows a microstructure without significant heterogeneities of binder distribution, while for the M-WC sample (Fig. 2b), a lower uniformity of the binder distribution is detected, showing an accumulation of the binder phase in some well dispersed regions. They can attain higher dimensions than the WC grains $(0.6-6 \mu \mathrm{m})$ as shown in Fig. $2 \mathrm{~b}$ where a large binder area of $\sim 9 \times 9 \mu \mathrm{m}^{2}$ can be discernible. The even distribution of the binder phase in the sputtercoated samples is really expected, due to the high initial uniformity of binder distribution, while the lower chemical homogeneity observed in the conventional prepared
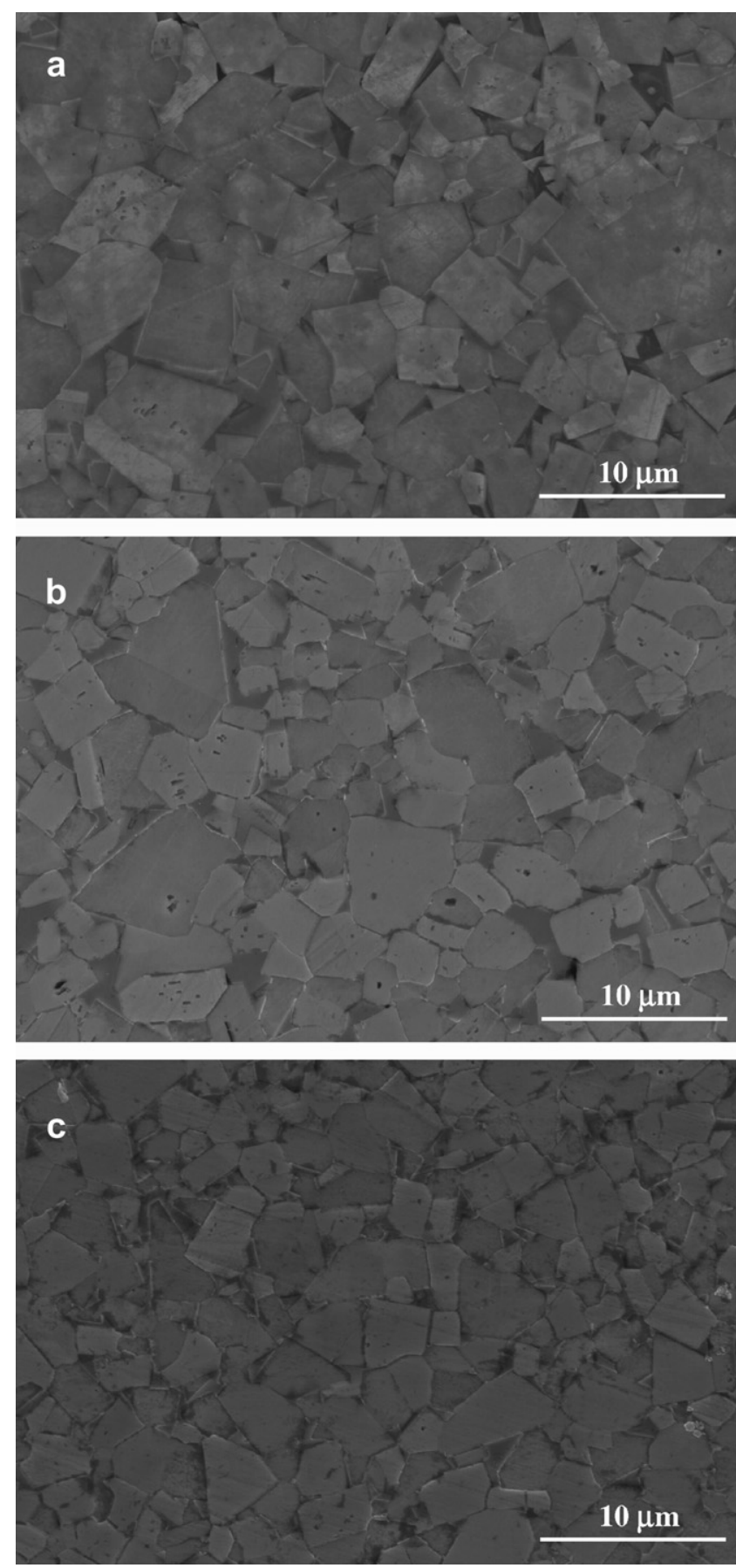

Fig. 3. SEM micrographs: (a) C-WC1, (b) C-WC2 and (c) M-WC.

compacts is commonly observed, as a result of insufficient mixing conditions, powder agglomeration and scale effects [23,24]. 
The SEM microstructures (Fig. 3) show polyhedral WC grains and a darker intergranular phase, corresponding to the rich Ni phase. The samples prepared from coated powders (C-WC1 and C-WC2) present very similar microstructures with coarser grains than the one prepared from mixed powders (M-WC). The values for the average grain size measured from the SEM micrographs are presented in Table 1, together with the range of particle/grain size before and after sintering. It can be observed that the grain size width in the sintered samples of coated powders is correspondent to the original particle size width, which means that no appreciable growth of the particle size occurred during sintering. The inhibition of particle growth during the sintering of the sputtered-coated powders has previously been reported and attributed to the highly uniform binder distribution attained in the sputtering process [1417]. The correspondent results for the M-WC compact show that the ranges of initial particle sizes develop to higher values, which is indicative of particle coarsening during sintering. Thus, the larger $\mathrm{C}-\mathrm{WC}$ grain size did not originate during the sintering process but came from differences in the powder particle size distribution of the coated and mixed powders, as shown in Table 1. Although the same WC powder was used as starting material for both processes, the mixing step used in the conventional preparation tends to desagregate some particles, resulting in a finer powder and a finer sintered compact.

\subsection{Test of the depth-sensing indentation method in a $W C-$ Co composite material}

In order to test the values of the mechanical properties determined by the depth-sensing indentation in multi-phase materials, a commercial $\mathrm{WC}-4 \% \mathrm{Co}$ sample was used as standard. The optical microstructure of the polished and etched surface is shown in Fig. 4. The standard sample is characterized by a fine microstructure with almost no pores and an average grain size of $\sim 2 \mu \mathrm{m}$ (Table 3 ).

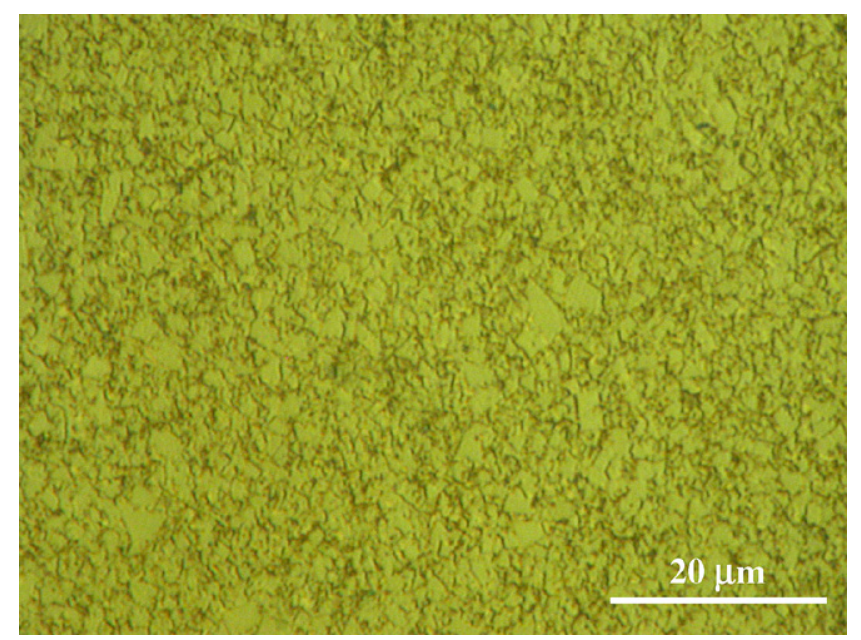

Fig. 4. Optical microstructure of the WC-Co composite.
Ultra-microhardness equipment was used to calculate the hardness and the Young's modulus, E, of the sample, using Eq. (3), taking $v=0.22$ for $\mathrm{WC}-4 \mathrm{wt} . \% \mathrm{Co}$ [25]. The following equation was proposed for determining the reduced Young's modulus [26,27]:

$E_{\mathrm{r}}=\frac{\sqrt{\pi}}{2} \frac{1}{\sqrt{A_{\mathrm{c}}}\left(C_{\mathrm{t}}-C_{\mathrm{f}}\right)}$

where $C_{\mathrm{t}}$ and $C_{\mathrm{f}}$ are the total compliance of the system and the frame compliance, respectively, and $A_{\mathrm{c}}$ is the contact area. In this equation, $E_{\mathrm{r}}$, is the reduced Young's modulus, which is a function of the Young's modulus and the Poisson's ratio, $v$, of the specimen (s) and the indenter (i), through:

$\frac{1}{E_{\mathrm{r}}}=\frac{1-v_{\mathrm{s}}^{2}}{E_{\mathrm{s}}}+\frac{1-v_{\mathrm{i}}^{2}}{E_{\mathrm{i}}}$

In recent years, efforts have been made to establish a reverse analysis algorithm for the evaluation of the plastic mechanical properties of materials. The principal developments in this area of investigation are related to the application of the finite element method to obtain dimensionless functions that relate the characteristic parameters of indentation loading-unloading curves to the mechanical properties obtained from the stress-strain curves [28]. Recently, a straightforward reverse analysis approach was proposed [19], which avoids the use of dimensionless functions. In a simplified description, this approach, which was used in the current investigation, consists of a direct comparison between experimental and numerical simulation indentation curves, in order to determine the yield stress, $\sigma_{\mathrm{y}}$, and the strain hardening coefficient, $n$, of the material. The Swift law was used in numerical simulations to describe the plastic behaviour:

$\sigma_{\mathrm{y}}=K\left(\varepsilon+\varepsilon_{0}\right)^{n}$

where $\varepsilon$ is the plastic strain and $K$ is a material parameter: $K=\sigma_{\mathrm{y}} / \varepsilon_{0}{ }^{n}\left(\varepsilon_{0}\right.$ is a constant, assumed as 0.005$)$. The calculated values of $\sigma_{\mathrm{y}}$ can thus be envisaged using this method and considering $\varepsilon=0.042$ (Fig. 5). The results are shown in Table 3, together with those resulting from conventional tests $^{2}$ done in this study and reported in the literature for specimens with similar chemical and physical characteristics $[25,29,30]$. The value obtained for the Young's modulus, $E$, by the depth-sensing indentation is equivalent to the one determined by dynamic excitation in this work, Table 3 . A very strong agreement is also observed with those reported in the literature in Table 3. The ultra-microhardness value determined by the depth-sensing method is not directly comparable with the HV30 values due to the large difference in the magnitude of the indentation loads, $500 \mathrm{mN}$ in the first method and $300 \mathrm{~N}$ in HV30 tests. Even

\footnotetext{
${ }^{2} E$ is typically determined by dynamic excitation of ultrasonic frequency longitudinal oscillations in a test bar and $\sigma_{\mathrm{y}}$ by compressive strength tests of a piece between two parallel carbide blocks, until failure occurs $[25,29,30]$.
} 
Table 3

Microstructural and mechanical characteristics of $\mathrm{WC}-\mathrm{Co}$ samples

\begin{tabular}{|c|c|c|c|c|c|c|c|c|}
\hline Co amount (wt.\%) & Grain size $(\mu \mathrm{m})$ & Density $\left(\mathrm{g} \mathrm{cm}^{-3}\right)$ & Hardness HV30 & Hardness (GPa) & $E(\mathrm{GPa})$ & $\sigma_{\mathrm{y}}(\mathrm{GPa})$ & $n$ & Ref. \\
\hline 4 & 2.5 & 15.3 & $1830 \pm 50$ & $22.0 \pm 0.2^{\mathrm{a}}$ & $\begin{array}{l}662 \pm 6^{a} \\
660\end{array}$ & $6.52^{\mathrm{a}}$ & $0.02^{\mathrm{a}}$ & In this work \\
\hline 4 & $2-4$ & 15.2 & 1900 & - & 660 & 6.00 & - & {$[25]$} \\
\hline 3 & $2-4$ & 15.3 & 1950 & - & 641 & 5.86 & - & [29] \\
\hline 4 & $2-4$ & - & 2000 & - & 665 & 7.10 & - & {$[30]$} \\
\hline
\end{tabular}

${ }^{a}$ Values obtained using depth-sensing indentation.

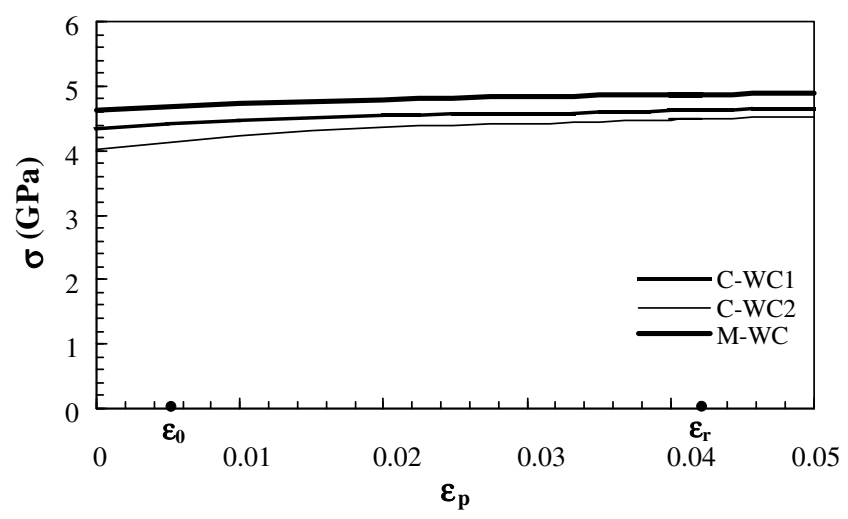

Fig. 5. Stress-plastic strain curves obtained in the reverse analysis showing the representative plastic strain value $\left(\varepsilon_{\mathrm{r}}\right)$ and the constant value $\left(\varepsilon_{0}\right)$.

so, it can be said that the determined value ( $H=22 \mathrm{GPa})$ concurs with the HV30 ( $H=18.3 \mathrm{GPa})$, being of the same order of magnitude but somewhat higher, as expected from the lower indentation load used. The yield compressive strength, $\sigma_{\mathrm{y}}$, using depth-sensing indentation, show very strong agreement with those resulting from conventional tests in the literature, Table 3. The hardening coefficient was very low, $n=0.02$, characteristic of brittle materials.

The good match between the previous values of the mechanical parameters determined by local depth-sensing tests in the WC-Co sample and those from macroscopic measurements is strongly indicative that the depth-sensing test can be used in homogeneous and fine size multiphase materials, since a representative indentation area was analysed overall. The number of tests needed to attain a representative indentation area in multiphase materials is dependent on microstructural characteristics, such as phase distribution and grain size. Increasing the degree of chemical homogeneity of the composite by increasing the uniformity of the phase distribution and the fineness of the microstructure will decrease the size of the representative area and, therefore, the number of measurements needed. In the case of the WC-Co standard, with fine microstructure ( $G=1.9 \mu \mathrm{m}$, smaller than the diagonal of each indentation, $\sim 8.4 \mu \mathrm{m}$, load $=500 \mathrm{mN}$ ), the conditions of a representative area were clearly fulfilled and a good match with the measurements made by the classical methods of mechanical characterization could be found.

Thus, it can be concluded that the applied method of depth-sensing indentation for the calculation of mechanical properties by depth-sensitive equipment, allows different mechanical characteristics used in material science/ mechanical engineering to be evaluated with precision.

\subsection{Mechanical characterization}

The mechanical characterization was carried out using depth-sensing indentation and Palmqvist toughness tests. Comparing the mechanical properties of the samples prepared by sputter-deposition (C-WC) and conventional wet milling (M-WC), (Table 4), with the correspondent properties of a WC-Co standard sample with equivalent amounts of binder (Table 3), the general trend points to lower values of hardness, $H$, Young's modulus, $E$, and yield strength, $\sigma_{\mathrm{y}}$, of the sputter-deposited samples (CWC). On the other hand, M-WC has only slightly different property values compared to the standard sample, due to similar microstructures but associated with the slight difference in mechanical properties between $\mathrm{Ni}$ rich binder and Co.

For the samples prepared from coated powders C-WC1 and $\mathrm{C}-\mathrm{WC} 2$, the mechanical properties are almost unaffected by the variation of the composition (Table 1), reflecting identical microstructures; high uniformity in the binder distribution and similar relative densities and grain size distributions (Fig. 3a and b and Table 2). In fact, the microstructure of cemented carbide is characterized by various parameters; phase volume fraction of carbide and binder, homogeneity, grain size, and degree of contact between individual grains, i.e. contiguity [31]. The only difference in these parameters for $\mathrm{C}-\mathrm{WC} 1$ and $\mathrm{C}-\mathrm{WC} 2$ is the binder content (Ni amount). The property that could be most affected by this difference must be the Young's modulus, but for the samples under analysis, the divergent values are included within the experimental error.

Comparing the properties of the samples prepared from coated powders (C-WC) with those of the conventionally prepared one (M-WC), the most significant deviation is in the Young's modulus values, $E$, where the M-WC composite has the highest value, despite the fact that it contains the highest $\mathrm{Ni}$ and total binder content, Table 1 . The difference attained cannot be included in Voigt-Reuss bounds [32], $E_{\text {Reuss }}-E_{\text {Voigt }}$ (calculated assuming the $E$ value of $\mathrm{Ni}$ ), as shown in Table 4 . The differences between the values of C-WC and M-WC Young's modulus cannot be attributed directly to the lower grain size of M-WC, as 
Table 4

Mechanical characteristics of $\mathrm{WC}-\mathrm{Ni} / \mathrm{Fe} / \mathrm{Cr}$ samples

\begin{tabular}{lllllrl}
\hline Samples & Hardness $(\mathrm{GPa})$ & Young's modulus $(\mathrm{GPa})$ & $\sigma_{\mathrm{y}}(\mathrm{GPa})$ & $n$ & $K_{\mathrm{C}}{ }^{\mathrm{a}}\left(\mathrm{MPa} \mathrm{m}^{1 / 2}\right)$ & $E_{\mathrm{Reuss}}-E_{\text {Voigt }}(\mathrm{GPa})$ \\
\hline C-WC1 & $17.0 \pm 0.4$ & $519 \pm 7$ & 4.32 & 0.03 & $9.6 \pm 0.3$ & $581-638$ \\
C-WC2 & $16.5 \pm 0.4$ & $520 \pm 9$ & 4.01 & 0.05 & $9.8 \pm 0.4$ & $546-622$ \\
M-WC & $17.8 \pm 0.2$ & $609 \pm 5$ & 4.62 & 0.02 & $11.0 \pm 0.4$ & $531-615$ \\
\hline
\end{tabular}

${ }^{\text {a }}$ Fracture toughness determined from measurements of the Palmqvist radial cracks.

for the light differences of the other properties evaluated. $E$ is very sensitive to extrinsic factors such as binder distribution. The higher the grain size the lower the specific surface, thus binder distribution may not be so efficient. However, the contiguity values (Table 2) are similar in both cases and the sintered density is favourable to the C-WC samples, also showing a lower tendency for porosity content higher than $1.5 \%$, which could significantly decrease the $E$ values. A possible explanation for the difference observed in $E$ values can be attributed to the chemical composition of WC grains. Diffusion of $\mathrm{Ni}$ to $\mathrm{WC}$ particles was observed during the high temperature vacuum brazing process $\left(1020-1120^{\circ} \mathrm{C}, 10^{-3} \mathrm{~Pa}\right)$ of $\mathrm{NiCrBSi}$ and $\mathrm{WC}-17 \mathrm{Co}$ powders on a mild steel substrate [33]. The preparation of nickel-tungsten bimetallic carbides was investigated and the results pointed to the formation of bimetallic carbides, where $\mathrm{Ni}$ enters in the tungsten carbide lattice in a metallic state without forming bonds with carbon [34]. Due to the formation of this type of solid solution a decrease of the carbide Young's modulus proportional to the Ni content will be expected. Thus the solid solution effect of $\mathrm{Ni}$ in WC and its effect on the Young's modulus could not be ignored in the sintered WC and Ni. Reporting to our results, during the powders' preparation stage or sintering process the Ni may diffuse more efficiently in coated powders than in traditional prepared ones, due to sputtering deposition conditions and to the nanocrystalline character of the $\mathrm{Ni}$ binder. Forthcoming studies will be performed in order to investigate the diffusion of sputtered $\mathrm{Ni}$ on WC surfaces. In addition, after sintering the Ni rich binder achieves a preferential orientation (200) that also contributes to a decrease in its Young modulus bearing in mind the polycrystalline value.

Palmqvist toughness testing [22] was performed using the cracks that appeared at the corners of Vickers indentations (load $=98 \mathrm{~N})$. This technique was successfully used because the contents of nickel are low. The values for the fracture toughness, $K_{\mathrm{C}}$, (Table 4 ) are very close for the three samples, although a slightly higher value was evaluated for the conventional WC sample (M-WC) as a direct consequence of the grain size differences.

\section{Conclusions}

Using this method of depth-sensing indentation for the calculation of mechanical properties in compressive strength is an interesting alternative to the conventional methods of mechanical characterization for composite materials, as it enables several properties to be determined from a reduced size sample. The characteristics obtained for a standard WC-Co sample using this method are very close to the published results of macroscopic characterizations for the determined values of hardness, $H$, Young's modulus, $E$, and yield stress, $\sigma_{\mathrm{y}}$.

The depth-sensing local characterization of sintered $\mathrm{WC}-\mathrm{Ni} / \mathrm{Fe} / \mathrm{Cr}$ coated powders showed that lower values of $E$ than those found in similar sintered conventional powders cannot be attributed to differences in grain size as for $H$ and $\sigma_{\mathrm{y}}$. The high binder uniformity and the nanometer-sized coating achieved by the sputter-deposition process is not the principal cause for the lowest values of $E$. The decrease in $E$ may have its origin in $\mathrm{Ni}$ diffusion into WC powders during the sputtering, which is enhanced during the sintering process. However, a preferential orientation could also have a role in $E$ values, contributing to their decrease. It is suggested that lower amounts of ductile binder will be needed to obtain convenient ductile properties in the composites prepared from sputtered powders, than when a conventional mixing process is used.

\section{Acknowledgements}

The authors wish to thank Bsc Mariana Matos for the help in the sputter-deposition, Prof. Valdemar Fernandes for the guidance of the depth-sensing indentation measurements and Dr. Filipe Oliveira for the assistance in HIP. The author C.M.F. gratefully acknowledges the financial support of the POCTI programme of the Portuguese Foundation for Science and Technology (FCT) and European Social Fund (FSE).

\section{References}

[1] Cornwall RG, German RM. Think bigger! The future is bright for MIM. Metal Powder Rep 2004;59(11):8-11.

[2] Viswanadham RK, Lindquist PG. Transformation-toughening in cemented carbides: Part I. Binder composition control. Metall Trans A 1987;18A:2163-73.

[3] Kakeshita T, Wayman CM. Martensitic transformations in cements with a metastable austenitic binder. Mater Sci Eng A 1991;141:209-19.

[4] Uhrenius B. Phase diagrams as a tool for production and development of cemented carbides and steels. Powder Metall 1992;35(3):203-10.

[5] González R, Echeberría J, Sánchez JM, Castro F. WC-(Fe, Ni, C) hardmetals with improved toughness through isothermal heat treatments. J Mater Sci 1995;30(13):3435-9.

[6] Cooper R, Manktelow SA, Wong F, Collins LE. The sintering characteristics and properties of hard metal with $\mathrm{Ni}-\mathrm{Cr}$ binders. Mater Sci Eng A 1988;A105-A106:269-73. 
[7] Tracey VA. Nickel in hardmetals. Int J Refr Metals Hard Mater 1992;11:137-49.

[8] Raghunathan S, Caron R, Friederichs J, Sandell P. Tungsten carbide technologies. Adv Mater Process 1996;4:21-3.

[9] Lardner E. Review of current hardmetals technology. Hardmetal Technol 1970:122-32.

[10] Taheri-Nassaj E, Mirhosseini SH. An in situ WC-Ni composite fabricated by the SHS method. J Mater Process Tech 2003;142:422-6.

[11] Kangwantrakool S, Shinohara K. New design of microstructure of WC- $\mathrm{Co} / \mathrm{TiC}-\mathrm{Al}_{2} \mathrm{O}_{3}$ composite materials by mechanical coating of particles. J Jpn Soc Powder Powder Metall 2002;49(12):1070-5.

[12] Brookes KJ. Complex shapes and hard-coated powders get over limit factors. Metal Powder Rep 2005;60(1):32-7.

[13] Castanho JM, Vieira MT, Fernandes CM, Senos AMR, Matos M. Improving the powder characteristics by sputtering surface modification. Vacuum, in press.

[14] Fernandes CM, Ferreira VM, Senos AMR, Vieira MT. Stainless steel coatings sputter-deposited on tungsten carbide powder particles. Surf Coat Technol 2003;176(1):103-8.

[15] Fernandes CM, Senos AMR, Vieira MT. Sintering of tungsten carbide particles sputter-deposited with stainless steel. Int J Refr Metals Hard Mater 2003;21:147-54.

[16] Fernandes CM, Senos AMR, Vieira MT. Study of sintering variables of tungsten carbide particles sputter-deposited with stainless steel. Mater Sci Forum 2004;455-456:295-8.

[17] Fernandes CM, Senos AMR, Castanho JM, Vieira MT. Effect of the $\mathrm{Ni}$ chemical distribution on the reactivity and densification of WC$(\mathrm{Fe} / \mathrm{Ni} / \mathrm{Cr})$ composite powders. Mater Sci Forum 2006;514 516:633-7.

[18] Fernandes CM, Senos AMR, Vieira MT. Particle surface properties of stainless steel-coated tungsten carbide powders. Powder Technol 2006;164:124-9.

[19] Antunes JM, Fernandes JV, Menezes LF, Chaparro BM. A new approach for reverse analyses in depth-sensing indentation using numerical simulation. Acta Mater 2007;55(1):69-87.

[20] Roebuck B, Bennett EG, Gee MG. Grain size measurement methods for WC/Co hardmetals. In: Bildstein H, Eck R, editors. Proceedings of the 13th International Plansee Seminar, Metallwerk Plansee, Reutte, vol. 2; 1993. p. 273.

[21] Golovchan VT, Litoshenko NV. On the contiguity of carbide phase in WC-Co hardmetals. Int J Refr Metals Hard Mater 2003;21:241-4.

[22] Ponton CB, Rawlings RD. Vickers indentation fracture toughness test, Part 1, review of literature and formulation of standardised indentation toughness equations. Mater Sci Technol 1989;5:865-72.

[23] Lin C, Kny E, Yuan G, Djuricic B. Microstructure and properties of ultrafine $\mathrm{WC}-0.6 \mathrm{VC}-10 \mathrm{Co}$ hardmetals densified by pressure-assisted critical liquid phase sintering. J Alloy Compd 2004;383:98-102.

[24] Lisovskii AF, Vishneskii AS, Sirota KI. An investigation of sintered WC-Ni hard alloys with an uneven distribution of the binder metal. Powder Metall Mater, Parts Coatings 1977;16(5):345-8.

[25] Brookes KJA. Hardmetals and other hard materials. 2nd ed. London: European Powder Metallurgy Association (EPMA), International Carbide Data; 1992.

[26] Newey D, Wilkins MA, Pollock HM. An ultra-low-load penetration hardness tester. J Phys E: Sci Instrum 1982;15:119-22.

[27] Oliver WC, Pharr GM. An improved technique for determining hardness and elastic modulus using load and displacement sensing indentation. J Mater Res 1992;7(6):1564-83.

[28] Dao M, Chollacoop N, Van Vliet KJ, Venkatesh TA, Suresh S. Computational modelling of the forward and reverse problems in instrumented sharp indentation. Acta Mater 2001;49(19):3899-918.

[29] Scussel HJ. Friction and wear of cemented carbides. ASM handbook, vol. 18. ASM Int; 1992. p. 796.

[30] Ingelstrom N, Nordberg $\mathrm{H}$. The fracture toughness of cemented tungsten carbides. Eng Fract Mech 1974;6:597-607.

[31] Roebuck B, Bennett EG. Phase size distribution in $\mathrm{WC}-\mathrm{Co}$ hardmetal. Metallography 1986;19:27-47.

[32] Hsieh CL, Tuan WH, Wu TT. Elastic behaviour of a model twophase material. J Eur Ceram Soc 2003;24(15-16):3789-93.

[33] Lu S-P, Know O-Y. Microstructure and bonding strength of WC reinforced Ni-base alloy brazed composite coating. Surf Coat Technol 2002;153:40-8.

[34] Xiao T, Wang H, York APE, Williams VC, Green MLH. Preparation of nickel-tungsten bimetallic carbide catalysts. J Catal 2002;209:318-30. 